\title{
Entimemas y principios andinos en los Mitos de Huarochirí
}

Enthymemes and Andean principles in the Myths of Huarochirí

Jorge Lagos, Luis Galdames

Universidad de Tarapacá, Departamento de Español, Casilla 6-D. Arica-Chile. e-mail: jlagos@uta.cl / lgaldame@uta.cl

Este trabajo, mediante un análisis semiótico sintáctico-pragmático, evidencia los entimemas que se relacionan con el verosímil de uno de los relatos contenido en los Mitos de Huarochirí.

Palabras clave: entimema, verosímil, apariencia, realidad, mito, Huarochirí.

The present work gives evidence through a semiotic syntactic-pragmatic analysis of the enthymemes which are likely related to one of the tales contained in the myths of Huarochirí.

Key words: enthymeme, likely, appearance, reality, myth, Huarochirí.

\section{INTRODUCCIÓN}

"Pienso que es bueno dejar hablar a los mitos, sobre todo si las cosas que se pretenden decir contradicen los tópicos aprendidos". René Girard. El Chivo Expiatorio.

El conjunto de relatos míticos quechuas sin título denominado el Manuscrito de Huarochirí es un corpus de piezas documentales recopiladas, según algunos, por el extirpador de idolatrías, Francisco de Avila, a inicios del siglo XVII en la provincia de Huarochirí (Centro del Perú), perteneciente en aquel entonces a la arquidiócesis de Lima. Sin embargo, el rol protagónico de de Avila ha sido fuertemente cuestionado desde la década de los noventa del recién pasado siglo.

El texto en cuestión se encontró en la Biblioteca Nacional de Madrid y fue parcialmente dado a conocer por Hermann Trimborn en los albores de la Segunda Guerra Mundial. Su primera traducción al español estuvo a cargo del literato y antropólogo peruano José María Arguedas, quien tituló al manuscrito como Dioses y Hombres de Huarochirí (1975). Su formación como antropólogo y un sólido conocimiento de la lengua originaria del Perú, producto de largos años de su vida compartidos con comunidades campesinas, no parecen haber sido avales suficientes y se le ha criticado con amabilidad haber realizado la traducción bajo la influencia de su vocación literaria (Murra 1983 y Rostworowski 1987). A nuestro entender, un juicio crítico de esta índole no aminora los méritos de su trabajo; más aún, su experiencia de vida en los Andes nos parece que otorga a su traducción una mirada "desde adentro" del mundo andino que muy pocos intelectuales pueden esgrimir a su favor.

Una segunda traducción al castellano la realizó el lingüista boliviano Jorge Urioste, quien rebautizó al manuscrito, ahora bajo el nombre de Hijos de Pariya Qaqa (1983).

Finalmente, y también en lengua española, nos encontramos con el trabajo realizado por el lingüista Gerald Taylor, quien en 1987 denominó su versión paleográfica del Manuscrito como Ritos y tradiciones de Huarochirí. Manuscrito quechua de comienzos del siglo XVII, versión utilizada en el presente trabajo.

En lo principal, el valor del Manuscrito radica en que se trata del único documento en runa simi, por tanto, un referente próximo al pensamiento mítico de los habitantes de la región de Huarochirí.

\section{CONSIDERACIONES PRELIMINARES}

El problema general que nos proponemos desarrollar en este trabajo puede enunciarse así: “¿Cuáles son y cómo se evidencian algunas categorías entimemáticas que son posibles de advertir en el discurso del relato "Capítulo $2^{\circ}$; Una tradición sobre Cuniraya Huiracocha" del Manuscrito de Huarochirí a 
través de temas que dicen relación con el engaño y con las situaciones tensionales entre los actantes que allí participan?

Es oportuno indicar que tanto el tema del engaño como el de las situaciones tensionales entre actantes, mantienen entre sí un maridaje cuya correlación resulta evidente en las apariencias del relato y no requiere mayores habilidades del lector para advertirlos.

Ambos temas parecen evidenciar un clamor doloroso y angustiante: el encuentro dramático entre el caos y el cosmos en una lucha que parece inevitable y con un final siempre incierto.

Existen, por otra parte, fundados antecedentes para sustentar como hipótesis que en el relato seleccionado del Manuscrito de Huarochirí, el verosímil permite develar los entimemas, y viceversa, los cuales se observan a través de los diálogos y razonamientos que sostienen algunos de los actantes y que construyen el discurso contenido en el relato.

Mediante el análisis de dichas formas, nos aproximaremos a un tipo de metafísica y de epistemología implícitas -premisas ausentes elaboradas desde los relatos- teniendo siempre presente la totalidad de los relatos contenidos en el Manuscrito aun cuando nos centremos en particular en el ya citado (v. supra).

Todo mito constituye un particular modo de relato y, en tanto tal, se sustenta en un verosímil (Barthes 1972 y 1974; Kristeva 1972; Todorov 1972 a y b) que dialécticamente se soporta con el entimema.

Según Todorov, para Platón y Aristóteles "lo verosímil es la relación del texto particular con otro texto, general y difuso, que se llama la opinión pública” (1972b: 13), el que hace las veces de filtro cultural y censurador de los posibles reales. Todorov siempre a propósito de lo verosímil, añade “...actualmente se hace predominante otro sentido: se hablará de verosimilitud de una obra en la medida en que ésta trate de hacernos creer que se conforma a lo real y no a sus propias leyes; dicho de otro modo, lo verosímil es la máscara con que se disfrazan las leyes del texto y que nosotros debemos tomar por una relación con lo verosímil” (1972b: 13). Entonces, si se sigue a Todorov, “...dos son los núcleos esenciales de lo verosímil: a) lo verosímil como ley discursiva inevitable y, b) lo verosímil como sistema de procedimientos retóricos, como máscara, que tiende a presentar estas leyes como otras tantas sumisiones o referentes" (Lagos 2003: 39).

Cualesquiera sean los ángulos de lo verosímil que se quiera destacar, existen dos asuntos que merecen ser señalados y acrecentados para los efectos del presente estudio: que el verosímil es cultural e histórico y que su propósito inmediato a través de la argumentación es la persuasión.

El primer asunto conduce a considerar que el verosímil es siempre arbitrario, pues muda sus demarcaciones de sentido según la época, los géneros literarios y la geografía de cada lugar. El discurso al que remite el buen sentido, lo socialmente aceptable, el sentido común (doxa), se da siempre en el marco de una cultura en un tiempo histórico dado.

J.B. Vico, entre los axiomas que propone al respecto, indica que "El sentido común es un juicio privado de reflexión, sentido de modo común por toda una clase, pueblo o nación, o por todo el género humano" (1964: 136). Como lo expresa Geertz con meridiana claridad, "la religión basa su teoría en la revelación, la ciencia en el método, la ideología en la pasión moral; pero el sentido común se basa frecuentemente en la afirmación de que en la realidad no se dispone de otra teoría que la de la vida misma" (1994: 95). En síntesis, el mundo es la autoridad.

El segundo asunto no es menor. El persuadir tiene que ver con dar sentido al discurso y otorgar sentido supone ser verosímil. Lo verosímil, entendido como sistema de procedimientos retóricos, es tratado en Aristóteles - según Roland Barthes-, como "una retórica de la prueba, del razonamiento, del silogismo aproximativo (entimema) [actuando allí como]una lógica voluntariamente degradada al nivel del 'público', es decir, del sentido común, de la opinión corriente" (1974: 18). De este modo, un conjunto de ideas serán consideradas como verosímiles a partir de algo probable, es decir, a partir de lo que el pueblo piensa.

En la lógica clásica (aristotélica en particular), estamos en presencia de un entimema cuando en el razonamiento deductivo no se halla alguna de sus partes explícita: una de sus premisas o la conclusión. Según el estagirita, el entimema es un "silogismo formado de proposiciones verosímiles o de signos" (Aristóteles 1947: 701) y que para el orador constituye el procedimiento más efectivo para realizar alguna demostración.

No obstante, es preciso recordar que el entimema se define por su carácter verosímil, buscando alcanzar en realidad la persuasión mediante la argumentación y no la demostración. En este sentido, el entimema arranca de un punto que no requiere ser probado y de allí se dirige hacia otro que necesita serlo (Lagos 2003). Un ejemplo de razonamiento entimemático, en el que se omite la premisa menor, es el siguiente: "Los dictadores son despiadados, pues todos los hombres ambiciosos son despiadados". Otro ejemplo: "Todos los marxistas son materialistas, por consiguiente, también este hombre es materialista" 
(DSF 1965: 142).

Para determinar si un entimema es o no válido, Copi sintetiza dos pasos necesarios. El primero consiste en agregar las partes del razonamiento que faltan; el segundo propone someter a un test de validez al silogismo resultante. Si falta una de las premisas, "puede ocurrir que solamente la adición de una proposición poco plausible haga el razonamiento válido, mientras que cualquier proposición plausible lo tornaría carente de validez" (1969: 207).

\section{ANÁLISIS SINTÁCTICO-PRAGMÁTICO DEL RELATO “CAPÍTULO 2, UNA TRADICIÓN SOBRE CUNIRAYA HUIRACOCHA".}

3.1. Determinación de secuencias y sus funciones. Estableceremos las secuencias (S) que reconocemos en el relato aludido anteriormente, así como las funciones (F) que en ellas se dan, esto es, la que abre el proceso (F.1), la que lo media (F.2) y una última que lo cierra (F.3). Encontramos siete (7) secuencias elementales (v. Romera Castillo 1974). A saber:

S.1

F.1 Cuniraya desea preñar a Cahuillaca

F.2 Cuniraya, mediante engaño, procede a preñar a Cahuillaca.

F.3 Cahuillaca queda preñada.

S.2

F.1 Cahuillaca da a luz a su hijo.

F.2 Cahuillaca desea conocer la identidad del padre de su hijo.

F.3 Cahuillaca convoca a los huacas y huillcas del lugar para saber quién de ellos es el padre.

S.3

F.1 Cahuillaca pide a su hijo que reconozca al padre.

F.2 El hijo reconoce a Cuniraya como su padre.

F.3 Cahuillaca no acepta que su hijo pueda haber sido engendrado por un ser (aparentemente) mísero.

S.4

F.1 Cahuillaca huye encolerizada con su hijo en dirección al mar.

F.2 Cuniraya exterioriza su imagen poderosa para que Cahuillaca, al verlo, se enamore de él.

F.3 Cuniraya persigue a Cahuillaca, sin que ella se percate de la verdadera identidad del primero.

S.5

F.1 Durante la persecución, Cuniraya va solicitando información en el camino a diversos animales sobre la posibilidad de alcanzar a Cahuillaca.

F.2 Cuando la respuesta de los animales satisface a Cuniraya, éste les ofrece felices augurios; cuando la respuesta es negativa, lo que reciben son maldiciones.

F.3 Cuniraya llega a orillas del mar sin encontrar a Cahuillaca, por lo que retorna a Pachacamac.

S.6

F.1 En Pachacamac encuentra Cuniraya a dos jóvenes hermanas.

F.2 Cuniraya viola a la menor de las jóvenes.

F.3 Cuniraya huye a la orilla del mar.

S.7

F.1 Urpayhuachac, madre de la joven violada, se indigna con Cuniraya.

F.2 Urpayhuachac persigue a Cuniraya para, mediante engaño, destruirlo.

F.3 Cuniraya, gracias a su astucia, huye de la ira de la madre y se dedica a deambular por el territorio engañando a huacas locales y hombres.

El conjunto de todas las secuencias anteriores puede resumirse en cuatro macroacciones:

1) Cuniraya fecunda a Cahuillaca mediante engaño.

2) Cahuillaca, al conocer la supuesta identidad del padre de su hijo y pensar que se trata de un ser 
miserable, huye de él con su hijo.

3) Cuniraya experimenta una doble frustración o fracaso: no logra alcanzar a Cahuillaca ni consigue que ésta conozca su verdadera identidad.

4) Cuniraya se dedica entonces a recorrer el territorio engañando a los waqa (huacas) y a la gente del lugar.

En la teoría de Bremond (1970), se adapta el esquema "Fechoría cometida" y "Hecho o daño a retribuir", según se desprende de las secuencias elementales. Veamos a continuación la distribución del esquema por secuencias:

Secuencias 1 a 4: Cuniraya desea preñar a Cahuillaca mediante engaño (Fechoría a cometer).

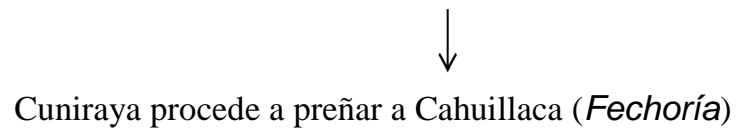

$\downarrow$

Cuniraya preña a Cahuillaca (Fechoría cometida) sin que ella conozca su identidad (Cahuillaca, intentando averiguar la identidad del padre de su hijo, retribuye la fechoría cometida huyendo de Cuniraya).

En la S.5, durante la persecución de Cuniraya a Cahuillaca, el primero va interrogando a diversos animales que encuentra en el camino sobre la posibilidad de alcanzar a Cahuillaca. Por turno, algunos animales le hacen ver a Cuniraya la imposibilidad de alcanzar a la madre de su hijo, mientras que otros le aseguran que su búsqueda será exitosa.

Tanto la zorrina como el zorro y el loro le señalan que ya no podrá Cuniraya alcanzar a Cahuillaca. Ante esta respuesta no deseada, Cuniraya les maldice.

Por el contrario, el cóndor, el puma, y el halcón le auguran el éxito en la búsqueda de Cahuillaca, por lo que reciben premios por parte de Cuniraya.

En ambas situaciones, de premio o de castigo, la tensión entre Cuniraya y los animales a quienes interroga es directa y se resuelve sin mediar engaño. No aplica en este caso, pues, el esquema de "Fechoría cometida $=$ Hecho a retribuir". No obstante, en las secuencias 6 y 7, el esquema funciona plenamente:

Cuniraya desea violar a una de las hijas de Urpayhuachac (Fechoría a cometer).

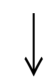

Cuniraya ataca sexualmente a una de las hijas de Urpayhuachac (Fechoría).

Cuniraya viola a la joven

(Fechoría cometida).

Urpayhuachac decide vengar a su hija $\quad=\quad$ (Hecho a retribuir).

Luego, los acontecimientos dan un giro completo y la madre agraviada se transforma ahora en madre vengadora. Es el turno para el protagonismo de la adversaria circunstancial de Cuniraya en un proceso que se puede visualizar, en los términos de Bremond, del modo siguiente:

Urpayhuachac, mediante engaño, desea vengar a su hija violada por Cuniraya

(Fechoría a cometer)

Urpayhuachac simula amabilidad para dar muerte a Cuniraya (Fechoría) 
Urpayhuachac se acerca a Cuniraya para darle muerte (no alcanza a producirse la Fechoría cometida $=$ Cuniraya, advirtiendo las intenciones de la mujer, huye del lugar mediante astucia o engaño (Hecho no retribuido).

Se ha visto que en las secuencias 1-4 el "Hecho a retribuir" se consuma a modo de huida por parte de Cahuillaca, dejando a Cuniraya sin la posibilidad de unirse a ella. En las secuencias 6 y 7 podemos advertir que el "Hecho a retribuir" tiene el mismo resultado: ahora se trata de la huida de Cuniraya de los intentos de Urpayhuachac por darle muerte.

No obstante, asoma una diferencia sustancial en las huidas referidas en ambos grupos de secuencias. En el primero, la huida de Cahuillaca ocurre porque ésta no es capaz de percatarse de la naturaleza poderosa de Cuniraya y huye creyendo hasta el final que esta entidad "sobrenatural" es en verdad un ser miserable. En el segundo grupo de secuencias, la huida de Cuniraya sucede porque éste sí advierte las intenciones vengativas de Urpayhuachac hacia él. Más aún, el poder de Cuniraya le otorga la oportunidad de engañar a la madre de la hija violada, fingiendo que ya regresa en circunstancias que lo que realmente concreta es su huida del lugar para seguir engañando a otros seres. Se produce así un proceso de engaño acompañado de malicia, una suerte de juego en la que no participan ni la rabia ni el rencor, sino simplemente la demostración sutil de poder por parte de quien es y se siente más poderoso que sus eventuales adversarios.

Observemos ahora las instancias estructurales que emergen cuando se utiliza el esquema "Perspectiva del engañador" y "Perspectiva del engañado" en las secuencias 1-4:

Perspectiva del engañador

Perspectiva del engañado

\begin{tabular}{|c|c|c|c|c|}
\hline $\begin{array}{l}\text { Víctima por } \\
\text { atrapar } \\
\text { (a Cahuillaca) }\end{array}$ & $\begin{array}{l}\text { Cuniraya es } \\
\text { poderoso y lo } \\
\text { disimula. }\end{array}$ & $\begin{array}{l}\text { Cuniraya no es } \\
\text { pobre } \\
\text { y simula serlo. }\end{array}$ & V/S & $\begin{array}{l}\text { Cahuillaca ve a } \\
\text { Cuniraya como pobre } \\
\text { y cree en ello. }\end{array}$ \\
\hline
\end{tabular}

En las secuencias 6 y 7, que refieren la tensión que se produce entre Urpayhuachac y Cuniraya por la violación que este último ha realizado en una de las hijas de la primera, el esquema funciona del modo que se indica a continuación:

Perspectiva del engañador

Víctima por
$\begin{aligned} & \text { atrapar (a } \\ & \text { Cuniraya) }\end{aligned}$ $\begin{cases}\text { Urpayhuachac es } & \text { Ella no es } \\ \text { vengativa y lo } & \text { amable y } \\ \text { disimula. } & \text { simula serlo }\end{cases}$

\section{Perspectiva del engañado}

Cuniraya conoce las
intenciones de
Urpayhuachac y no cree en
su amabilidad.

La "Perspectiva del engañador" funciona, como se aprecia, de modo similar tanto en las secuencias 14 como en las secuencias 6-7. Sin embargo, desde la "Perspectiva del engañado", la situación varía. En efecto, en las secuencias 1-4, la "Víctima por atrapar" (Cahuillaca en este caso) cree que la apariencia miserable de Cuniraya corresponde a la realidad y no ve el engaño. Por el contrario, en las secuencias 6-7, la "Víctima por atrapar", Cuniraya, jamás se deja sorprender por el intento de engaño de Urpayhuachac, dominando en todo momento la situación. En este sentido, Cuniraya, en tanto entidad poderosa, posee la capacidad de engañar a terceros menos poderosos que él y de advertir, del mismo modo, los intentos engañosos de los mismos hacia él.

3.2. Determinación de los actantes. De acuerdo al modelo que nos propone A.J. Greimas (1976), la distribución actancial que nos presenta el relato en cuestión puede evidenciarse del siguiente modo. Recordemos las cuatro macroacciones para la aplicación del modelo y observemos cómo se distribuyen los actantes.

Primera macroacción: “ Cuniraya fecunda a Cahuillaca mediante engaño”. 
Sujeto: Cuniraya

Objeto: Preñar a Cahuillaca

Remitente: Cuniraya (él es el demandante de la acción).

Destinatario: Cuniraya

Opositor: No lo hay.

Ayudante: la lúcuma y la capacidad de engaño mediante metamorfosis de Cuniraya.

La ausencia de opositor se origina en la capacidad de simulación y de disimulación, respectivamente, que posee Cuniraya. Es posible que si Cahuillaca hubiese llegado a conocer desde el inicio el poder de Cuniraya, cabe la posibilidad de que ella misma se hubiere presentado como Opositor.

Segunda macroacción: "Cahuillaca, al conocer la supuesta identidad del padre de su hijo y pensar que se trata de un ser miserable, huye de él con su vástago".

Sujeto: Cahuillaca

Objeto: Impedir las consecuencias que traería aparejadas el contraer vínculos con un ser miserable.

Remitente: el prejuicio de Cahuillaca que identifica apariencia con realidad.

Destinatario: Cahuillaca y su hijo.

Oponente: el poder de Cuniraya, y los animales que lo alientan a alcanzarla mediante noticias favorables.

Ayudante: Cuniraya con su capacidad de simulación que logra convencer a Cahuillaca de su identidad miserable.

Tercera macroacción: "Cuniraya experimenta una doble frustración o fracaso: no logra alcanzar a Cahuillaca ni consigue que ésta conozca su verdadera identidad".

Sujeto: Cuniraya.

Objeto: Ser reconocido en todo su esplendoroso poder por Cahuillaca.

Remitente: Cuniraya.

Destinatario: Cuniraya (la satisfacción de su deseo).

Oponente: Cuniraya (su propia capacidad de engaño que no logra revertir) y la creencia de Cahuillaca referida a la imposibilidad de unión con un ser aparentemente inferior a ella y los animales que le dan malas noticias cuando la persigue.

Ayudante: los animales que le dan buenas noticias sobre la posibilidad de alcanzar a Cahuillaca.

Cuarta macroacción: "Cuniraya se dedica entonces a recorrer el territorio engañando a los waqa y a la gente del lugar".

Sujeto: Cuniraya.

Objeto: Continuar engañando a los waqa y gente del lugar.

Remitente: Cuniraya (su propia identidad que lo obliga a engañar a terceros).

Destinatario: Cuniraya.

Oponente: No hay (mientras encuentre seres inferiores en poder a él, procederá a engañarlos).

Ayudante: Cuniraya (su propio poder de simulación y de disimulación).

3.3. Categorías entimemáticas. En primer término, en el relato se puede apreciar que los temas del "engaño" y de las "situaciones tensionales" se hallan imbricados en un mismo tejido. Dicho de otro modo, no ocurre lo uno sin lo otro, introduciéndose así el riesgo o la posibilidad de la intromisión de vínculos y relaciones desestructuradores del orden y, por ende, favorecedores de la instalación del caos en su reemplazo (véase, por ejemplo, el principio cultural andino del pachakutí). Excepción notable la constituye el diálogo entre Cuniraya y los animales que encuentra en el camino durante la persecución a Cahuillaca. En efecto, allí la tensión no se halla mediatizada por celada alguna: premios y castigos surgen prístinos y directamente ligados a lo favorable o desfavorable de las respuestas que dan los animales a la pregunta de Cuniraya por Cahuillaca.

Las tensiones poseen expresión espacial. Diversos acontecimientos del relato ocurren entre la costa y el mar. Así tenemos la huida de Cahuillaca en dirección al océano o, en la persecución de Cuniraya por Urpayhuachac, la huida del primero desde la costa hacia la serranía andina, proceso de movimiento que hace recordar el principio cultural andino de mita (turno), así como principios vinculados a espacio como el de tinqu (tensión) y el de punqu (umbral).

Otro plano fuerte que se muestra característico de la época y de la matriz cultural del lugar, dice relación con la tensión entre apariencia y realidad. Cuniraya simula ser pobre y disimula todo su poder cuando engaña a terceros. Las relaciones se hacen conflictivas precisamente por la intervención del 
engaño, que distorsiona lo habitual y cotidiano y lo vuelve inestable.

También se advierte un significativo plano pasional, que se moviliza por las pulsiones destructivas de Urpayhuachac hacia Cuniraya, pretendiendo utilizar la celada para satisfacer su deseo de venganza. Pero, además, se hacen presente las pulsiones eróticas, como las que gatillan la violación que Cuniraya realiza en una de las hijas de Urpayhuachac, o cuando éste busca preñar a Cahuillaca mediante engaño.

Las "situaciones tensionales" y "el engaño" parecen sustentarse en la creencia de la comunidad cultural de Huarochirí en orden a suponer que entre apariencia y realidad debería producirse una necesaria correspondencia. De este modo, el cosmos conservaría su equilibrio y no dejaría lugar a la participación del caos.

Este orden admitiría diferenciadas jerarquías que no soportan su disolución por la vía de la confusión que supondría el otorgar determinados atributos a quien no corresponde, generando con ello expectativas de rol que tampoco se condicen con la "realidad". Sin embargo, es menester tomar algunas precauciones y no detenernos aquí en el análisis. En efecto, en el plano normativo, este orden de las cosas puede verse violentado al ser vulnerado por el no cumplimiento de otras normas que no están explícitas en el relato. Así, cuando Cuniraya es marginado por la comunidad (y particularmente por Cahuillaca), se transgreden pautas culturales andinas y cristianas al unísono.

Como sabemos, para la cultura andina la existencia del huaccho (huérfano) alude a aquél que no tiene redes parentales activas, lo que lo constituye en un "pobre", puesto que por oposición la riqueza en los Andes deriva de la gente que es capaz de movilizarse para las faenas del agro y del pastoreo de animales. Entonces, por propia conveniencia comunitaria, el abandonar a un hombre sólo es inadmisible para la ética y las relaciones productivas andinas.

De otro lado, desde la mirada cristiana que se hace presente en el relato, la carencia de caridad frente al desposeído es también ausencia de una de las virtudes más caras al mandato bíblico.

De este modo, si se estima por parte del logos andino que apariencia y realidad se corresponden, ello no es óbice para marginar al "pobre". Precisamente, esta exclusión es la que introduce el riesgo de la pérdida de los equilibrios, provocando por mano humana la armonía que teje en unidad lo que la racionalidad occidental distingue como si se tratare de dos mundos contrapuestos: el "natural" y el "sobrenatural".

En esta dirección podemos aseverar, respetando el orden secuencial del relato, que cuando Cuniraya se presenta como hombre pobre en la comunidad que comparte Cahuillaca y es despreciado por ella provocando la necesidad en él de mostrar su verdadera identidad, la premisa mayor no explícita pero sí compartida por el común es, en primer término: 'Todos los miembros de la comunidad de Huarochirí deben ayudar a los pobres'.

En segundo lugar, y a propósito del cambio de imagen de Cuniraya que se viste con sus mejores galas para mostrar su verdadera fisonomía, es posible arribar a una segunda premisa mayor implícita que reza así: 'Todos los seres que tienen apariencia de pobre son pobres'.

Con posterioridad, el relato nos describe el diálogo que Cuniraya sostiene con distintos animales para indagar sobre las posibilidades de alcanzar a Cahuillaca, premiando a aquellos que lo alientan en la búsqueda y castigando a aquellos animales que le responden que ya no será posible para Cuniraya alcanzar a la mujer.

Se puede advertir de este diálogo que la situación descrita se desprende lógicamente de otro juicio que tampoco se expone en el texto, a saber: 'Todos los animales de Huarochirí pueden ser premiados o castigados por Cuniraya'.

Durante el mismo juego de relaciones entre Cuniraya y los animales, es posible percatarse con toda certeza que los vínculos son autoritarios. Nada hay en los diálogos que indique una actitud racional, de verdadera escucha frente a los argumentos que proporcionan los animales a Cuniraya. De este modo, si se quiere comprender qué idea, qué creencia subyace a esta forma de interacción social, se debe pensar en un juicio como el siguiente: 'Todas las divinidades de Huarochirí se relacionan autoritariamente con los animales'.

Finalmente, y en lo que dice relación con diferentes pasajes del relato, se advierte que Cuniraya utiliza el engaño como mecanismo habitual de relación con los demás. Si esto es así, entonces podemos proponer que la idea, el supuesto implícito a modo de entimema es el que sigue: 'Todas las waqas y personas del área de Huarochirí pueden ser engañados por Cuniraya'.

\section{CONCLUSIONES}

La hipótesis postulada propuso que el verosímil permite develar los entimemas -y viceversa- que se 
hallan presentes en el relato en cuestión considerando el corpus total de los relatos de Huarochirí, pero emergió un asunto que superó este propósito y nuestra propia expectativa.

Surge un conjunto breve, pero contundente, de ideas subyacentes en el relato, otorgando sentido y significado al saber, al sentido común y a la racionalidad de los habitantes de Huarochirí.

Ambos temas, el del "engaño" y el de las "situaciones tensionales", se fueron interdigitando en las fisonomías y en las filigranas, algunas veces finas y en otras ocasiones gruesas, que orientan los principios culturales del tinqu, de la reciprocidad, del pachakuti y de la mita (v. supra). El conflicto, la tensión del tinqu, suele amenazar con el caos y por ende abre las compuertas para que invada dominante el pachakuti. El vínculo autoritario entre las divinidades de Huarochirí, las wakas menores y los pobladores andinos, está marcado por el principio de la reciprocidad que, según acusa el relato, en ocasiones no se cumple con él.

Finalmente, la estructura del propio relato y la ocurrencia del conflicto entre Cuniraya y Cahuillaca evidencian el turno de las cosas, la vigencia y la presencia de la mita, que abre procesos y los cierra para dar origen a un nuevo ciclo.

Algunos de estos mismos principios culturales participan en todos los demás relatos del Manuscrito de Huarochirí. El segundo relato, por ejemplo, el $5^{\circ}$ del Manuscrito, está regido por el tinqu y por las relaciones autoritarias, al igual que el resto de los relatos; pero, además, el texto del relato es el ámbito que releva la presencia de una divinidad (Huatyacuri) que presenta algunos atributos cristianos, evidenciando el periodo de extirpación de idolatrías que contextualiza el relato.

La crítica normativa que persiste en el conjunto de relatos tiene como constante transversal la crítica por la ausencia de la vigencia del principio de reciprocidad por parte de los comuneros. Así, el relato tercero nos presenta nuevamente el desapego a la tradición de la reciprocidad. Pariacaca, la divinidad, es la entidad contralora que vela por la mantención de los equilibrios y que castiga severamente a los que no cumplen con las obligaciones que permiten la reproducción de la comunidad.

El $8^{\circ}$ relato del Manuscrito pone en primer plano la tensión entre dos divinidades poderosas (uno de los hermanos de Pariacaca y Huallallo Carhuincho), en donde el tinqu, o la lucha deberá finalizar con la derrota de una de ellas. Aquí éste u otros conflictos no son eventuales, representan la precariedad cotidiana de la existencia. Queda aquí de manifiesto el rol intrascendente del individuo en un contexto social comunitario; el "hombre triste" es un simple espectador del espectáculo de lucha que prometen las poderosas deidades de Huarochirí. En los relatos de Huarochirí, entonces, la cultura del lugar otorga peculiaridad a las expresiones y dimensiones del conflicto.

El pensamiento mítico, que muestra rostros humanos y divinos en el relato, supone la existencia de la renovación, de la reiteración vía oralidad, de la mita perpetua que es la propia renovación. Por otra parte, los relatos de Huarochirí, en general, nos presentan divinidades que asoman a veces como los agoreros (oráculos) en la tragedia griega, y ello ocurre con ocasión de las permanentes apariciones de personas pobres (o divinidades que simulan ser personas y pobres) y que la comunidad no acoge, gatillando el castigo de los espíritus del lugar. Este punto pone de relieve un atributo principal de los comuneros de Huarochirí: para ellos, apariencia y realidad son una misma cosa; de allí brota la posibilidad de ser engañados.

¿Cuáles son las premisas ausentes, entonces, ante un eventual razonamiento elaborado desde la lógica de los propios relatos del corpus?. A nuestro juicio, las narraciones enfatizan algunas ideas y creencias subyacentes que desnudan en parte importante los ejes conceptuales de la "enciclopedia" (Eco 1979) de los habitantes de Huarochirí:

'Todos los habitantes de Huarochirí son comuneros que deben ayudar a los pobres'.

'Todos los seres que tienen apariencia de pobre son pobres'.

'Todos los habitantes (humanos o divinos) de Huarochirí son seres que se relacionan autoritariamente entre sí'.

'Algunas divinidades de Huarochirí son seres que poseen la capacidad de engañar'.

'Algunas divinidades de Huarochirí son seres capaces de fingir pobreza'.

'Todas las divinidades de Huarochirí son capaces de sanar a los enfermos'.

'Todas las divinidades de Huarochirí tienen la capacidad de castigar a personas y animales'.

'Todas las divinidades de Huarochirí tienen la capacidad de premiar a las personas y los animales'.

'Todos los habitantes de Huarochirí son comuneros que asimilan apariencia y realidad'.

'Todos los habitantes de Huarochirí son comuneros que deben respetar el principio cultural de la reciprocidad para evitar ser castigados'.

'Todas las divinidades de Huarochirí son seres que desencadenan el caos cuando no se respeta el orden establecido'. 
'Todos los habitantes de Huarochirí son comuneros que conocen los principios culturales andinocoloniales que gobiernan el cosmos y evitan el caos'.

Estas son las premisas formalmente ausentes en los relatos y que hacen evidentes los juicios entimemáticos que explican la racionalidad de los relatos de Huarochirí.

El pensamiento mítico es parte fundamental del patrimonio cultural de una sociedad; supone renovación y también recuperación del pasado, posee la capacidad de maravillarnos, de retornarnos a los orígenes para así no perder lo cotidiano. Tenerlo presente como objeto de preocupación científica y filosófica es asumir que la memoria es parte de la identidad de los pueblos, aunque ello suponga, como en el caso de Huarochirí, que se nos remita a una sociedad y cultura que vivió en precario equilibrio y en donde el espíritu de los comuneros parece haber estado colonizado por el miedo que suscitan el frío, el hambre, la soledad y lo desconocido.

\section{OBRAS CITADAS}

Arguedas, J. M. 1975. Dioses y hombres de Huarochirí. México: Siglo Veintiuno Editores.

Aristóteles. 1947. Primeros analíticos. Obras completas. Buenos Aires: Ediciones Florida.

Barthes, R. 1972. "El efecto de realidad”. Lo Verosímil. Buenos Aires: Editorial Tiempo Contemporáneo.

— 1974. Investigaciones retóricas. La antigua retórica. Buenos Aires: Editorial Tiempo Contemporáneo.

Bremond, C. 1970. "La lógica de los posibles narrativos". Análisis estructural del relato. Buenos Aires: Editorial Tiempo Contemporáneo.

Copi, I. 1969. Introducción a la lógica. Buenos Aires: Eudeba.

Eco, U. 1989. La estructura ausente. Introducción a la semiótica. Barcelona: Editorial Lumen.

Geertz, C. 1994. Conocimiento local. Ensayos sobre interpretación de las culturas. Barcelona: Ediciones Paidós.

Greimas, A. 1976. Semántica estructural. Investigación Metodológica. Madrid: Gredos.

Kristeva, J. 1972. La productividad llamada texto". Lo Verosímil. Buenos Aires: Tiempo Contemporáneo.

Lagos, J. 2003. La metalepsis y la actividad cooperativa del sector empírico. Estudios Filológicos. Anejo No 16. Valdivia: Facultad de Filosofía y Humanidades, Universidad Austral de Chile.

Murra, J. 1983. Presentación”. J. Urioste. Hijos de Pariya Qaqa. La tradición oral de WaruChiri. New York: Syracuse University.

Romera Castillo, J. 1974. El comentario de textos semiológicos. Madrid: Sociedad Española de Librería.

Rostworowski, M. 1987. "Presentación”. G. Taylor. Ritos y tradiciones de Huarochirí. Lima: Instituto de Estudios Peruanos-Instituto Francés de Estudios Andinos.

Taylor, G. 1987. Ritos y tradiciones de Huarochirí. Manuscrito quechua de comienzos del siglo XVII. Lima: Instituto de Estudios Peruanos-Instituto Francés de Estudios Andinos.

Todorov, T. 1972a. "Introducción”. Lo Verosímil. Buenos Aires: Tiempo Contemporáneo.

1972b. "Lo verosímil que no se podría evitar". Lo Verosímil. Buenos Aires: Tiempo Contemporáneo.

Urioste, G. 1983. Hijos de Pariya Qaqa. La tradición oral de WaruChiri. New York: Syracuse University.

Vico, J. B. 1964. Principios de una ciencia nueva en torno a la naturaleza común de las naciones. Buenos

Aires: Aguilar. 